\title{
CUHSO. CULTURA-HOMBRE-SOCIEDAD
}

ISSN 07I6-I 557 | e-ISSN 07I9-2789 | VOL. 23 | NÚM. I | 3 I DE JULIO DE 2013

\section{Contenidos}

Editorial ..................................................................................... 7

\section{ARTÍCULOS CIENTÍFICOS}

LUCÍA TROTTA Y PAULA SOZA ROSSI

Metodología dialógica e interdisciplina en la extensión universitaria.

Reflexiones acerca de una experiencia

RICARDO ORELLANA OLIVARES Y JOSÉ MANUEL MERINO ESCOBAR

Predictores asociados a variaciones en puntajes Simce

en la región del Biobío

RAÚL GONZÁLEZ MEYER

Revisitando la historia de las teorías del desarrollo

BERNARDO GUERRERO JIMÉNEZ

Desarrollo andino: sustentable y con identidad 93

MÓNICA DE MARTINO

Género y trabajo social: algunos desafíos I09

\section{DOCUMENTOS Y TESTIMONIOS}

ALFREDO CAÑAS PINOCHET

El gillatún de Traitraico de I 89I 127 